\title{
Corrigendum: The paternal ancestry of Uttarakhand does not imitate the classical caste system of India
}

Neetu Negi, Rakesh Tamang, Veena Pande, Amrita Sharma, Anish Shah, Alla G Reddy, Satti Vishnupriya, Lalji Singh, Gyaneshwer Chaubey and Kumarasamy Thangaraj

Journal of Human Genetics (2016) 61, 843; doi:10.1038/jhg.2016.48

Correction to: Journal of Human Genetics (2016) 61, $167-172$; doi:10.1038/jhg.2015.121; published online 29 October 2015.

Since the publication of the above article, the authors of the above paper have noticed an error in one of the contributing author's name. 'Amrita Sharma' should have been 'Amrita Nandan'.
The authors would like to apologize for this mistake. 